ISSN 0103-9954

\title{
COMPOSIÇÃO NUTRICIONAL DE PROCEDÊNCIAS E PROGÊNIES DE ERVA-MATE (Ilex paraguariensis St. Hil.) CULTIVADAS EM LATOSSOLO VERMELHO DISTRÓFICO ${ }^{1}$
}

\author{
NUTRITIONAL COMPOSITION OF PROVENANCES AND PROGENY OF MATE \\ (Ilex paraguariensis St. Hil.) CULTIVADED IN DISTROFIC RED OXISOILS
}

\author{
Elaine Vivian Oliva ${ }^{2}$ Carlos Bruno Reissmann ${ }^{3}$ Sergio Gaiad ${ }^{4}$ Edilson Batista de Oliveira ${ }^{5}$ \\ José Alfredo Sturion 6
}

\begin{abstract}
RESUMO
Ilex paraguariensis St. Hil. é uma espécie florestal de grande importância socioeconômica para os estados sulinos do Brasil. Objetivou-se com a presente pesquisa, avaliar o estado nutricional de procedências (IvaíPR e Barão de Cotegipe-RS) e suas respectivas progênies em Latossolo Vermelho distrófico, no município de Ivaí - PR. O delineamento experimental utilizado foi de blocos ao acaso, com quatro repetições, tendo como tratamento duas procedências e cinco progênies. Analisaram-se os macronutrientes, micronutrientes, $\mathrm{Al}$ e Na. Os teores foliares de N, P, K, Ca e Mg foram considerados satisfatórios, sendo que os nutrientes $\mathrm{N}, \mathrm{P}, \mathrm{Ca}$ e $\mathrm{Mg}$ apresentaram diferença significativa para ambas as procedências analisadas. Dentro das procedências, as progênies de Ivaí, destacaram diferença significativa para os nutrientes $\mathrm{N}, \mathrm{P}, \mathrm{K}, \mathrm{Ca}$ e $\mathrm{Mg}$. Porém, para as progênies de Barão de Cotegipe, constatou-se diferença significativa apenas para os teores de $\mathrm{Ca}$ e $\mathrm{Mg}$. Para as duas procedências, os teores foliares de $\mathrm{Fe}, \mathrm{Cu}$ e $\mathrm{Mn}$ foram considerados satisfatórios. A concentração de $\mathrm{Zn}$ foi considerada baixa e a de B elevada. Os teores de Al foram considerados normais para a espécie. Quanto ao $\mathrm{Na}$, não se observou diferença significativa entre procedências. Os teores de $\mathrm{Zn}, \mathrm{Fe}, \mathrm{Cu}$, bem como de $\mathrm{Al}$ e $\mathrm{Na}$, diferiram estatisticamente entre as progênies de Barão de Cotegipe e Ivaí. A procedência de Ivaí apresentou teores mais elevados tanto de macro como de micronutrientes, comparativamente à procedência de Barão de Cotegipe, indicando que um programa de melhoramento genético poderá refletir significativamente na melhoria da qualidade da erva-mate com fins de qualidade nutricional humana. Comparando as médias do peso da massa verde das procedências, há ganho significativo da copa da procedência de Barão de Cotegipe, o que não é acompanhado pelo peso da massa seca de 100 folhas.
\end{abstract}

Palavras-chave: análise química; nutrição de plantas; progênies.

\section{ABSTRACT}

Ilex paraguariensis St. Hil. is a forest species of great socioeconomic importance for the southern states of Brazil. This study aimed to assess the nutritional status of provenances (Ivaí, in Paraná state and Barão de Cotegipe, in Rio Grande do Sul state) and their progenies in a soil in the municipality of Ivaí, PR state. The experimental design was randomized blocks with four replications, taking as treatment two distinct

1 Artigo extraído da dissertação da primeira autora apresentada ao Programa de Pós-graduação em Ciência do Solo da Universidade Federal do Paraná.

2 Bióloga, Doutoranda pelo Programa de Pós-Graduação em Engenharia Florestal, Universidade Federal do Paraná, Av. Pref. Lothário Meissner, 900, Jardim Botânico, Campus III, CEP 80210-170, Curitiba (PR), Brasil. Bolsista Capes. elainevivian@ufpr.br

3 Engenheiro Florestal, Dr., Professor Colaborador da Universidade Federal do Paraná, Rua dos Funcionários, 1540, CEP 80035-050, Curitiba (PR), Brasil. reissman@ufpr.br

4 Engenheiro Florestal, Dr., Pesquisador da Embrapa Florestas, Estrada da Ribeira, Km 111, CEP 83411-000, Colombo (PR), Brasil. sergio.gaiad@embrapa.br

5 Agrônomo, Dr., Pesquisador da Embrapa Florestas, Estrada da Ribeira, Km 111, CEP 83411-000, Colombo (PR), Brasil. edilson.oliveira@embrapa.br

6 Engenheiro Florestal, Dr., Pesquisador da Embrapa Florestas, Estrada da Ribeira, Km 111, CEP 83411-000, Colombo (PR), Brasil. jose.sturion@embrapa.br

Recebido para publicação em 16/08/2010 e aceito em 19/04/2013 
provenances and five progenies. When analyzed, the macronutrients, micronutrients, $\mathrm{Al}$ and $\mathrm{Na}$. Foliar $\mathrm{N}, \mathrm{P}, \mathrm{K}, \mathrm{Ca}$ and $\mathrm{Mg}$ were considered satisfactory, and the $\mathrm{N}, \mathrm{P}, \mathrm{Ca}$ and $\mathrm{Mg}$ showed significant differences for both analyzed provenances. Within provenances, progenies of Ivaí highlighted significant differences for the nutrients $\mathrm{N}, \mathrm{P}, \mathrm{K}, \mathrm{Ca}$ and $\mathrm{Mg}$. But for the progenies of Barão de Cotegipe, a significant difference was found only for $\mathrm{Ca}$ and $\mathrm{Mg}$. For both provenances, foliar $\mathrm{Fe}, \mathrm{Cu}$ and $\mathrm{Mn}$ were considered satisfactory. The concentration of $\mathrm{Zn}$ was considered low and B high. Aluminum contents were considered normal for the species. In regard to $\mathrm{Na}$, there was no significant difference among provenances. The contents of $\mathrm{Zn}, \mathrm{Fe}, \mathrm{Cu}$ and $\mathrm{Al}$ and $\mathrm{Na}$ differed among the progenies of Barão de Cotegipe and Ivaí. The provenance of Ivaí showed higher levels of both, macro and micronutrients, compared to Barão de Cotegipe, indicating that a breeding program could significantly improve the quality of mate for human nutrition purposes. Comparing the average weight of green mass of the provenances, there is a significant gain in the crown of Barão de Cotegipe provenance which is not accompanied by the dry weight of 100 leaves. Keywords: chemical analysis; plant nutrition; progenies.

\section{INTRODUÇÃO}

A família Aquifoliaceae apresenta aproximadamente 600 espécies, dentre essas, 60 espécies são encontradas no Brasil, a qual pertence à erva-mate (MACCARI e MAZUCHOWSKI, 2000). A erva-mate Ilex paraguariensis St. Hil., é uma planta de origem sul-americana encontrada predominantemente nos estados sulinos do Brasil, nordeste da Argentina, parte oriental do Paraguai (GREIZERSTEIN et al., 2000; OLIVEIRA e ROTTA, 1985), também em pontos isolados no Uruguai (GREGIANINI e WINGE, 2000). No mundo, os únicos países produtores de erva-mate são Brasil, Argentina e Paraguai (COSTA, 2005). Neste contexto apresenta grande variabilidade genética (WINGE, 1997; COELHO, 2000) e fenotípica (RESENDE et al., 1995).

O Brasil produziu um total de 218.102 toneladas de folhas de erva-mate de ervais nativos do país (IBGE, 2009), destacando o Estado do Paraná como o principal produtor com participação de $71,8 \%$ no mercado nacional. Na sequência, encontra-se o Estado de Santa Catarina com 36.493 toneladas, Rio Grande do Sul com 24.764 toneladas e Mato Grosso do Sul com 282 toneladas. A erva-mate é explorada economicamente em aproximadamente 596 municípios, envolvendo 180 mil propriedades rurais e mais de 710 mil trabalhadores diretos (RODIGHERI et al., 2005).

$\mathrm{Na}$ cultura da erva-mate, folhas e ramos são colhidos sucessivamente a cada dois anos. Este procedimento tem por consequência intensa exportação foliar tanto de macro como de micronutrientes, requerendo a sua reposição. Com o emprego de técnicas específicas e controle do manejo é possível estimar estas perdas. A quantificação da biomassa, segundo Vogel et al. (2006), constitui a base para o conhecimento do estoque e dinâmica dos nutrientes na floresta e, também como manejar ecossistemas de forma sustentável. Para Caldeira et al. (2001), o acúmulo de biomassa é afetado por fatores ambientais e inerentes à própria planta.

A análise química foliar é uma das melhores técnicas para avaliar o estado nutricional das plantas (ULRICHS e HILLS, 1990) e, em conjunto com a análise de solo, pode trazer melhores informações para recomendação de fertilizantes (MALAVOLTA et al., 1997). Segundo Floss (1997), os ervais implantados apresentam baixa produtividade, devido às técnicas inadequadas de cultivo e manejo e, principalmente pela baixa qualidade do material genético utilizado na produção de mudas. Deve-se também mencionar que a concentração de nutrientes pode apresentar diferenças dentro da espécie mesmo quando cultivadas em ambientes iguais (HARIDASAN, 2000). A concentração de nutrientes nas folhas pode representar mais do que $30 \%$ do total da árvore (VAN DER DRIESSCHE, 1984), sendo que a composição química da planta varia com o tipo de solo, clima, época de amostragem, idade da planta e, principalmente, pelas características genéticas (MALAVOLTA, 1980; BRONDANI et al., 2008).

Neste contexto, a presente pesquisa teve por objetivo quantificar teores dos macro e micronutrientes de duas procedências e cinco progênies cultivadas em Latossolo Vermelho distrófico.

\section{MATERIAL E MÉTODO}

O experimento foi instalado em 1997 por pesquisadores da Embrapa Florestas, na Fazenda Vila Nova da ervateira Bitumirim, em Ivaí - PR, 
situada entre os paralelos $25^{\circ} 15^{`}$ Sul e $50^{\circ} 45^{\circ}$ Oeste (IBGE, 2009). A região é caracterizada pela formação de Floresta Ombrófila Mista. O solo é um Latossolo Vermelho distrófico de textura argilosa (RESENDE et al., 2000). O clima é do tipo Cfb, conforme a classificação de Köppen, a temperatura média anual varia entre $17^{\circ} \mathrm{C}$ e $18^{\circ} \mathrm{C}$, com uma precipitação média anual de aproximadamente 1500 mm (IAPAR, 1994).

$\mathrm{O}$ experimento contém sete procedências, sendo seis do Paraná e uma do Rio Grande do Sul. Cada procedência possui cinco progênies com seis plantas por parcela. O delineamento experimental é o de blocos ao acaso, com arranjo de progênies dentro de procedências, com quatro repetições. $\mathrm{O}$ espaçamento de plantio é de $2 \mathrm{~m}$ x $3 \mathrm{~m}$.

Para o presente estudo foram utilizadas duas procedências, sendo uma de origem do estado do Rio Grande do Sul (Barão de Cotegipe, BC) e outra de origem local (Ivaí, IV). A coleta de material para análise foi realizada oito anos após a implantação. As amostras de folhas foram coletadas em agosto de 2005, na porção mediana da copa (REISSMANN et al., 1999) com exposição norte, visando à máxima exposição luminosa (ZÖTTL, 1973; JONES e CASE, 1990). Foram utilizadas as três plantas mais homogêneas de cada parcela, considerando-se a morfologia da copa e a sanidade das folhas, totalizando 12 indivíduos por progênie em um conjunto de 100 folhas/planta. As amostras da massa da copa foram pesadas diretamente no campo em balança comercial e expressas como massa fresca $\mathrm{kg} / \mathrm{ha}$. As amostras foram lavadas com água deionizada e secas à temperatura de $60^{\circ} \mathrm{C}$ até peso constante. Após esse processo, as amostras foram moídas à fração de $1 \mathrm{~mm}$ e armazenadas em frascos herméticos.

A análise do $\mathrm{N}$-total foi efetuada pelo método da digestão via úmida, micro-kjeldahl, conforme descrito por Martins e Reissmann (2007). Para os nutrientes $\mathrm{P}, \mathrm{K}, \mathrm{Ca}, \mathrm{Mg}, \mathrm{Fe}, \mathrm{B}, \mathrm{Mn}, \mathrm{Cu}, \mathrm{Zn}$, bem como o $\mathrm{Al}$ e $\mathrm{Na}$, a análise química foi efetuada após a incineração em mufla a $500^{\circ} \mathrm{C}$ (Adaptado de JONES e CASE, 1990) e solubilização em ácido clorídrico, em concentração de $3 \mathrm{~mol}$. L $\mathrm{L}^{-1}$ (PERKIN-ELMER, 1976). A determinação do $\mathrm{P}$ foi realizada por colorimetria com vanadatomolibdato de amônio e o B determinado pelo método calorimétrico usando azometina $-\mathrm{H}$, em espectrofotômetro UV/VIS (SILVA, 1999). O K e $\mathrm{Na}$ foram determinados por fotometria de emissão e $\mathrm{Ca}, \mathrm{Mg}, \mathrm{Mn}, \mathrm{Cu}, \mathrm{Zn}$ e Al, por espectrofotometria de absorção atômica (PERKIN-ELMER, 1976) sendo que o Al foi determinado em chama de acetileno e óxido nitroso (SILVA, 1999).

As amostras de solo foram coletadas com trado holandês à profundidade $0-20 \mathrm{~cm}$, na projeção da periferia da copa de cada planta. Coletaram-se três subamostras por parcela, agrupando-as em uma amostra composta por unidade experimental, totalizando 40 amostras de solo. Após a coleta, as amostras foram secas ao ar e, peneiradas posteriormente em peneira de $2 \mathrm{~mm}$ (TFSA). Para a determinação do $\mathrm{C}$ utilizou-se o dicromato de sódio mais ácido sulfúrico; para o $\mathrm{K}, \mathrm{P}$ e $\mathrm{Na}$ o extrator Mehlich 1; para os elementos $\mathrm{Ca}, \mathrm{Mg}$ e Al utilizouse o extrator $\mathrm{KCl}$, em concentração de $1 \mathrm{~mol} . \mathrm{L}^{-1} \mathrm{e}$ para a determinação do $\mathrm{pH}$ em $\mathrm{CaCL}_{2}$ utilizou-se o cloreto de cálcio a 0,01 M (EMBRAPA, 1979).

Os micronutrientes $\mathrm{Fe}, \mathrm{Cu}, \mathrm{Mn}$ e $\mathrm{Zn}$, foram extraídos com ácido cítrico a 1\% (REISSMANN e ZÖTTL, 1987). Realizou-se a pesagem de 10 $\mathrm{g}$ das amostras de solo, em frascos de $250 \mathrm{~mL}$ acrescentando $100 \mathrm{~mL}$ de ácido cítrico a $1 \% \mathrm{em}$ cada amostra. Adicionalmente, $\mathrm{Cu}$ e $\mathrm{Zn}$ também foram determinados em extratos de $\mathrm{HCl}, 0,1 \mathrm{~N}$ (SILVA, 1999). Os atributos, expressos como média da área, encontram-se na Tabela 1.

Os dados da análise química da planta, por tratamento, representados por macro, micronutrientes e $\mathrm{Al}$ e $\mathrm{Na}$ foram submetidos à análise de variância, teste de médias por Duncan,

TABELA 1: Atributos químicos do solo à profundidade de $0-20 \mathrm{~cm}$ coletados na projeção da periferia da copa de cada planta (média de 40 amostras).

TABLE 1: Soil chemical properties at a depth of $0-20 \mathrm{~cm}$ were collected in the projection of the periphery of the crown of each plant (average of 40 samples).

\begin{tabular}{|c|c|c|c|c|c|c|c|c|c|c|c|c|c|}
\hline \multirow{3}{*}{$\begin{array}{c}\mathrm{pH} \\
\mathrm{CaCl}_{2} \\
3,7\end{array}$} & $\mathrm{Al}$ & $\mathrm{H}+\mathrm{Al}$ & $\mathrm{Ca}$ & $\mathrm{Mg}$ & $\mathrm{K}$ & $\mathrm{Na}$ & $\mathrm{N}$ & $\mathrm{P}$ & $\mathrm{Fe}$ & $\mathrm{Mn}$ & $\mathrm{Cu}$ & $\mathrm{Zn}$ & $\mathrm{C}$ \\
\hline & \multicolumn{6}{|c|}{------------cmol $/ \mathrm{dm}^{-3}$----------- } & g. $\mathrm{kg}^{-1}$ & mg.dm ${ }^{-3}$ & \multicolumn{4}{|c|}{---------mg.kg-1--------- } & g.dm ${ }^{-3}$ \\
\hline & 5,4 & 18,2 & 0,7 & 0,6 & 0,4 & 0,1 & 2,7 & 1,4 & 333 & 32,8 & 1,20 & 0,60 & 32,1 \\
\hline
\end{tabular}

Em que: Teores de $\mathrm{Cu}=2,12 ; \mathrm{Zn}=0,65$ obtidos com HCL $0,1 \mathrm{~mol} \mathrm{~L}^{-1}$. 
TABELA 2: Análise granulométrica do solo do experimento (média de 40 amostras).

TABLE 2: Particle size analysis of the experiment (average of 40 samples)

\begin{tabular}{|c|c|c|}
\hline Areia & Silte & Argila \\
\hline \multicolumn{3}{|c|}{-----------------------------------------------g kg } \\
\hline 19,8 & 253,9 & 726,3 \\
\hline
\end{tabular}

utilizando para isso o programa estatístico SANEST (ZONTA e MACHADO, 1985).

\section{RESULTADOS E DISCUSSÃO}

$\mathrm{Na}$ Tabela 3 são apresentados os dados de massa da copa e massa de 100 folhas, com os respectivos coeficientes de determinação e correlação no sentido de se obter uma estimativa da primeira. Ao analisar estatisticamente as características, massa da copa e massa de 100 folhas, observa-se que a primeira característica não diferiu estatisticamente entre as progênies das procedências de Ivaí e Barão de Cotegipe, enquanto a segunda apresentou diferenças significativas entre as progênies das procedências analisadas (Tabela 3). A massa verde para a procedência de Ivaí variou de 10,05 a 11,82 t/ha entre as progênies, porém, para Barão de Cotegipe a massa variou de 12,45 a 15,41 t/ha, destacando assim, a procedência de Barão de Cotegipe com maior peso da massa fresca.
No sentido de se obter uma estimativa antecipada da produtividade foi testada a correlação entre massa de 100 folhas e massa fresca da copa.

A massa seca de 100 folhas também permite estabelecer estimativas da exportação de nutrientes através da sua expressão em termos de conteúdo foliar (FIEDLER, NEBE e HOFFMANN, 1973). Como se pode observar, os coeficientes são baixos na maioria das progênies, não possibilitando essa estimativa ao todo como esperado. No entanto, quando agrupadas, as médias quanto à massa da copa e de 100 folhas por progênie/procedência de cada repetição (três plantas por progênie $\mathrm{x}$ quatro repetições $=12$ plantas, obtém-se quatro médias), sendo possível, assim, obter uma estimativa, para as progênies 11, 25 e 53 (Figuras 1A, B e C).

Constatou-se maior estimativa de correlação positiva $(r=0,93)$ para a progênie 25 , correlação negativa $(\mathrm{r}=-0,80)$ para a progênie 11 e positiva $(\mathrm{r}=0,77)$ para a progênie 53. Isto pode significar que, se for encontrada uma forma de selecionar

TABELA 3: Médias de massa fresca e massa seca da copa e massa de 100 folhas de progênies e procedências de erva-mate e respectivos coeficientes de correlação e determinação.

TABLE 3: Mean fresh mass and dry mass of the crown and mass of 100 leaves of progenies and provenances of mate, and their coefficients of correlation and determination

\begin{tabular}{|c|c|c|c|c|c|}
\hline \multirow{2}{*}{ PROGÊNIE } & \multicolumn{2}{|c|}{ MASSA DA COPA } & \multirow{2}{*}{$\begin{array}{c}\text { MASSA DE } 100 \\
\text { FOLHAS } \\
\mathrm{g}\end{array}$} & \multirow{2}{*}{$\begin{array}{l}\text { COEFICIENTE } \\
\text { CORRELAÇÃOO }\end{array}$} & \multirow{2}{*}{$\begin{array}{c}\text { COEFICIENTE } \\
\text { DETERMINAÇÃO }\end{array}$} \\
\hline & $\mathrm{kg}$ & $\mathrm{t} / \mathrm{ha}$ & & & \\
\hline $04 \mathrm{IV}$ & $6,03 \mathrm{a}$ & $10,05 \mathrm{a}$ & $40,7 \mathrm{a}$ & 0,27 & 0,0717 \\
\hline $08 \mathrm{IV}$ & $7,09 \mathrm{a}$ & $11,82 \mathrm{a}$ & $34,3 \mathrm{ab}$ & 00,7 & 0,0046 \\
\hline $10 \mathrm{IV}$ & $5,90 \mathrm{a}$ & 9,83 a & $42,7 \mathrm{a}$ & 0,11 & 0,0127 \\
\hline $11 \mathrm{IV}$ & $6,54 \mathrm{a}$ & $10,90 \mathrm{a}$ & $33,9 \mathrm{ab}$ & 0,80 & 0,6251 \\
\hline $25 \mathrm{IV}$ & $6,83 \mathrm{a}$ & $11,38 \mathrm{a}$ & $31,2 \mathrm{~b}$ & 0,93 & 0,8584 \\
\hline $53 \mathrm{BC}$ & $7,47 \mathrm{a}$ & $12,45 \mathrm{a}$ & $38,7 \mathrm{ab}$ & 0,77 & 0,6014 \\
\hline $59 \mathrm{BC}$ & $8,74 \mathrm{a}$ & 14,57 a & $42,1 \mathrm{a}$ & 0,29 & 0,0855 \\
\hline $61 \mathrm{BC}$ & $7,74 \mathrm{a}$ & $12,90 \mathrm{a}$ & $35,2 \mathrm{ab}$ & 0,35 & 0,1254 \\
\hline $65 \mathrm{BC}$ & $9,25 \mathrm{a}$ & $15,41 \mathrm{a}$ & $32,0 \mathrm{~b}$ & 0,21 & 0,0453 \\
\hline $69 \mathrm{BC}$ & $8,57 \mathrm{a}$ & $14,28 \mathrm{a}$ & $31,2 \mathrm{~b}$ & 0,15 & 0,0212 \\
\hline MÉDIA - IV & $6,5 \mathrm{~B}$ & $10,83 \mathrm{~B}$ & $36,6 \mathrm{~A}$ & - & - \\
\hline MÉDIA - BC & $8,3 \mathrm{~A}$ & $13,83 \mathrm{~A}$ & $35,8 \mathrm{~A}$ & - & - \\
\hline
\end{tabular}

Em que: Para cada procedência, médias com as mesmas letras minúsculas, na vertical, não diferem estatisticamente ao nível de 5\% pelo teste de Duncan. Médias com as mesmas letras maiúsculas, na vertical, não diferem estatisticamente ao nível de $1 \%$ pelo teste de Duncan, no âmbito das procedências. IV = Ivaí, $\mathrm{BC}=$ Barão de Cotegipe. 


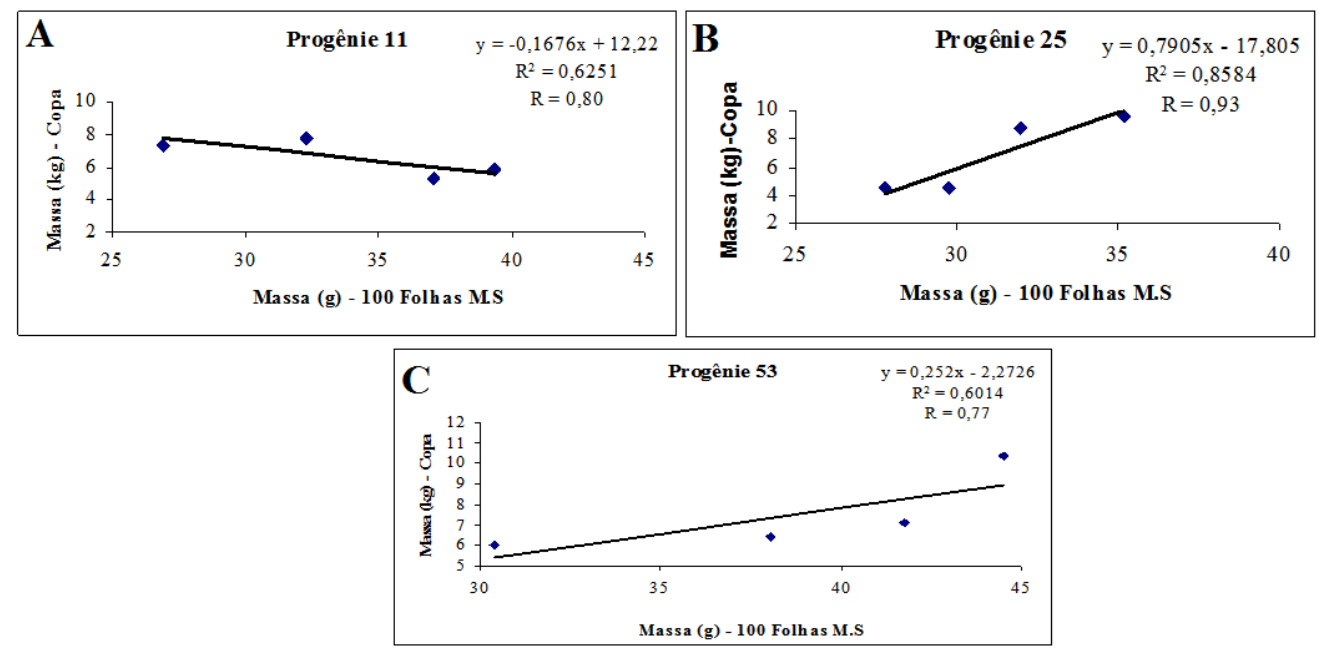

FIGURA 1: Correlação de Pearson entre massa (g) de 100 folhas e o massa (kg) da copa de progênies de erva-mate.

FIGURE 1: Pearson Correlation between mass $(\mathrm{g})$ of 100 plants and mass $(\mathrm{kg})$ crown of progenies of mate.

de forma mais abrangente o material da copa, ou aumentar a representatividade do número de folhas, esta hipótese da estimativa da massa fresca da copa pode ser satisfeita. Sendo assim, comparando as médias da massa fresca das procedências, há ganho significativo da copa da procedência de Barão de Cotegipe, o que não é acompanhado pela massa seca de 100 folhas.

O teor de $\mathrm{N}$ foliar médio, entre procedências, variou de 17,8 a 20,1 $\mathrm{g} \mathrm{kg}^{-1}$ (Tabela 4), sendo que o teor mais elevado foi determinado para a procedência de Barão de Cotegipe. Os teores de $\mathrm{N}$ nas progênies de Ivaí variaram de 15,3 a 21,6 $\mathrm{g} \mathrm{kg}^{-1}$. Nas progênies de Barão de Cotegipe, os teores de $\mathrm{N}$ ficaram em torno de $19,8 \mathrm{~g} \mathrm{~kg}^{-1}$. Uma informação relevante é que o $\mathrm{N}$ é o nutriente exportado em maior quantidade pela colheita (WISNIEWSKI et al., 1996) sendo limitante à produtividade (ZAMPIER, 2003). Além do que o $\mathrm{N}$ é importante elemento correlacionado à cafeína, tanino e teobromina (BORILLE et al.,

TABELA 4: Teores médios de macronutrientes $\left(\mathrm{g} \mathrm{kg}^{-1}\right)$ de progênies de erva-mate da procedência de Ivaí - PR e Barão de Cotegipe - RS cultivadas em Ivaí - PR.

TABLE 4: Average levels of macronutrients $\left(\mathrm{g} \mathrm{kg}^{-1}\right)$ of mate of the progenies of Ivaí, PR state and Barão de Cotegipe, RS state, grown in Ivaí, PR state.

\begin{tabular}{|c|c|c|c|c|c|}
\hline PROGÊNIE & $\mathrm{N}$ & $\mathrm{P}$ & $\mathrm{K}$ & $\mathrm{Ca}$ & $\mathrm{Mg}$ \\
\hline $04 \mathrm{IV}$ & $16,7 \mathrm{bc}$ & $1,6 \mathrm{~b}$ & $10,5 \mathrm{~b}$ & $13,2 \mathrm{~b}$ & $5,8 \mathrm{ab}$ \\
\hline $08 \mathrm{IV}$ & $15,3 \mathrm{c}$ & $1,9 \mathrm{a}$ & $13,2 \mathrm{a}$ & $13,0 \mathrm{~b}$ & $6,4 \mathrm{a}$ \\
\hline $10 \mathrm{IV}$ & $17,3 \mathrm{bc}$ & $1,6 \mathrm{~b}$ & $13,0 \mathrm{a}$ & $7,1 \mathrm{c}$ & $5,5 \mathrm{ab}$ \\
\hline $11 \mathrm{IV}$ & $21,6 \mathrm{a}$ & $1,4 \mathrm{c}$ & $12,6 \mathrm{ab}$ & $6,5 \mathrm{c}$ & $5,0 \mathrm{~b}$ \\
\hline $25 \mathrm{IV}$ & $17,9 \mathrm{~b}$ & $1,5 \mathrm{bc}$ & $10,4 \mathrm{~b}$ & $16,0 \mathrm{a}$ & $6,5 \mathrm{a}$ \\
\hline $53 \mathrm{BC}$ & $20,7 \mathrm{a}$ & $1,2 \mathrm{a}$ & $11,5 \mathrm{a}$ & $10,4 \mathrm{a}$ & $4,2 \mathrm{a}$ \\
\hline $59 \mathrm{BC}$ & $19,7 \mathrm{a}$ & $1,3 \mathrm{a}$ & $13,7 \mathrm{a}$ & $6,3 \mathrm{~b}$ & $2,5 \mathrm{~b}$ \\
\hline $61 \mathrm{BC}$ & $20,4 \mathrm{a}$ & $1,3 \mathrm{a}$ & $12,9 \mathrm{a}$ & $6,9 \mathrm{~b}$ & $2,6 \mathrm{~b}$ \\
\hline $65 \mathrm{BC}$ & $21,0 \mathrm{a}$ & $1,3 \mathrm{a}$ & $11,9 \mathrm{a}$ & $7,9 \mathrm{~b}$ & $2,5 \mathrm{~b}$ \\
\hline $69 \mathrm{BC}$ & $18,6 \mathrm{a}$ & $1,2 \mathrm{a}$ & $11,3 \mathrm{a}$ & $7,2 \mathrm{~b}$ & $2,1 \mathrm{~b}$ \\
\hline Teor Médio - IV & $17,8 \mathrm{~B}$ & $1,6 \mathrm{~A}$ & $11,9 \mathrm{~A}$ & $11,2 \mathrm{~A}$ & $5,8 \mathrm{~A}$ \\
\hline Teor Médio - BC & $20,1 \mathrm{~A}$ & $1,3 \mathrm{~B}$ & $12,3 \mathrm{~A}$ & $7,8 \mathrm{~B}$ & $28 \mathrm{~B}$ \\
\hline
\end{tabular}

Em que: Para cada procedência, médias com as mesmas letras minúsculas, na vertical, não diferem estatisticamente ao nível de 5\% pelo teste de Duncan, no âmbito das progênies dentro de cada uma das procedências. Médias com as mesmas letras maiúsculas, na vertical, não diferem estatisticamente ao nível de $1 \%$ pelo teste de Duncan, no âmbito das procedências. Em que: IV = Ivaí, $\mathrm{BC}=$ Barão de Cotegipe. 
2005). Os resultados apresentados neste estudo são satisfatórios quando comparados com Reissmann et al., (1999) que encontraram teores médios de 17,0 a $18,5 \mathrm{~g} \mathrm{~kg}^{-1}$ em povoamentos de oito anos de idade localizados na região de MandiritubaPR. Os teores médios de $\mathrm{N}$ obtidos nesse estudo são altos quando comparados com Ribeiro et al., (2008) que obtiveram teor médio de $12,4 \mathrm{~g} \mathrm{~kg}^{-1}$ em tratamento testemunha e teores de 7,1 e 13,0 g $\mathrm{kg}^{-1}$ em tratamentos com adubação nitrogenada de 40 e $60 \mathrm{~kg} \mathrm{~N} \mathrm{ha}^{-1}$, respectivamente. Teores baixos em relação à pesquisa de Borille et al. (2005), que obtiveram teores variando de 28,69 a 31,50 $\mathrm{g} \mathrm{kg}^{-1}$.

Entre as procedências analisadas houve diferença significativa para o $\mathrm{P}$, com teores médios de 1,3 e $1,6 \mathrm{~g} \mathrm{~kg}^{-1}$ de matéria seca (Tabela 4). Os teores de $\mathrm{P}$ nas progênies de Ivaí variaram de 1,4 a $1,0 \mathrm{~g} \mathrm{~kg}^{-1}$. No entanto, para as progênies de Barão de Cotegipe, os teores de $\mathrm{P}$ foram, em média, de 1,2 a $1,3 \mathrm{~g} \mathrm{~kg}^{-1}$. As progênies de Ivaí apresentaram, em média, maiores teores de $\mathrm{P}$ em relação às de Barão de Cotegipe, $1,65 \mathrm{~g} \mathrm{~kg}^{-1}$ e $1,25 \mathrm{~g} \mathrm{~kg}^{-1}$, respectivamente. Os teores de $\mathrm{P}$ em erva-mate encontrados são frequentemente baixos (REISSMANN et al., 1983), devido, possivelmente, à característica da espécie e, por apresentar mecanismos de adaptação para baixos níveis de $\mathrm{P}$ no solo, conforme pode ser constatado na Tabela 1. Em plantas de erva-mate avaliadas aos cinco anos de idade, os teores variaram de 0,82 a $0,92 \mathrm{~g} \mathrm{~kg}^{-1}$ (RACHWAL, 2000). Em análises mais abrangentes, os dados da pesquisa, podem ser considerados satisfatórios quando comparados com os dados de ervais de média a alta produtividade, variando respectivamente entre 1,2 a $1,8 \mathrm{~g} \mathrm{~kg}^{-1}$ (FOSSATI e REISSMANN, 1997). Em estudos desenvolvidos por Sosa (1994), abrangendo as regiões de Misiones e Corrientes, na Argentina, ficaram estabelecidos teores médios em torno de 1,5 $\mathrm{g} \mathrm{kg}^{-1}$. Finalmente, comparando os teores foliares de $\mathrm{P}$ desse estudo com outras espécies florestais em geral (MALAVOLTA et al., 1997), os mesmos são comparáveis a algumas das espécies florestais relacionadas. Os teores mais baixos nas progênies de Barão de Cotegipe refletem, possivelmente, a diferença genotípica e não um nível de deficiência.

Os teores médios de $\mathrm{K}$ foram estatisticamente iguais para as duas procedências. Nas progênies de Ivaí, os teores variaram de 10,4 a $13,2 \mathrm{~g} \mathrm{~kg}^{-1}$. Para as progênies de Barão de Cotegipe, não houve diferenças estatísticas para os teores de $\mathrm{K}$ (Tabela 4). De modo geral, os teores de K variam bastante em erva-mate (REISSMANN et al., 1997;
SOSA, 1994). Os dados presentes superam em muito os obtidos por Carneiro et al. (2006) cujos teores máximos foram de $7,0 \mathrm{~g} \mathrm{~kg}^{-1} \mathrm{e}$, teores foliares de $8,0 \mathrm{~g} \mathrm{~kg}^{-1}$ obtidos por Pandolfo et al. (2003). Os dados são comparáveis aos de Radomski et al. (1992) que obtiveram teores variando de 11,6 a $14,7 \mathrm{~g} \mathrm{~kg}^{-1} \mathrm{em}$ folhas maduras de erva-mate em sistema de Faxinal. Os altos teores em relação às outras pesquisas podem ser um reflexo dos elevados teores encontrados no solo (Tabela 1). No entanto, ainda assim, os resultados obtidos na presente pesquisa são baixos quando comparados com Sosa (1994), que estabeleceu teores médios de 19,2 g $\mathrm{kg}^{-1}$. Considerando que os teores correspondem aproximadamente à mesma época de amostragem, a variação bastante ampla destes teores pode ser atribuída a aspectos distintos do sítio e manejo dos povoamentos (SOSA, 1994).

Os teores de Ca variaram de 7,8 a 11,2 g $\mathrm{kg}^{-1}$ entre as procedências de Barão de Cotegipe e Ivaí, respectivamente. As progênies de Ivaí foram responsáveis pelos teores mais elevados de $\mathrm{Ca}$ variando de 6,5 a $16,0 \mathrm{~g} \mathrm{~kg}^{-1}$, sendo o teor mais elevado encontrado na progênie 25 , enquanto que, em progênies de Barão de Cotegipe, obtiveram-se teores de 6,3 a $10,4 \mathrm{~g} \mathrm{~kg}^{-1}$, constatando o teor mais elevado para a progênie 53 (Tabela 4).

Os teores de $\mathrm{Ca}$ podem ser considerados altos na presente pesquisa, quando comparados com Rachwal et al. (2000) que, ao analisarem amostras foliares expostas a diferentes intensidades luminosas, encontraram teores variando de 5,1 a $5,8 \mathrm{~g} \mathrm{~kg}^{-1} \mathrm{e}$ Carneiro et al. (2006), que obtiveram teores médios de 5,69 $\mathrm{g} \mathrm{kg}^{-1}$. O Ca apresenta baixa mobilidade não sendo redistribuído na planta (PEREIRA et al., 2000). Conforme Malavolta et al. (1997), esse nutriente é essencial para manter a integridade das estruturas das membranas e das paredes celulares. Quando comparados com outras pesquisas apresentam níveis na faixa de interpretação normal para a exigência nutricional da cultura. Por exemplo, Fossati e Reissmann (1997), ao analisarem amostras aos sete anos de idade de diferentes ervais, de média a alta produtividade, alocados em uma topossequência, obtiveram teores variando de 7,3 a $10,9 \mathrm{~g} \mathrm{~kg}^{-1}$. Com o aumento de saturação de bases em Cambissolo Álico, Reissmann et al. (1997) determinaram níveis foliares de 4,6 a 5,3 $\mathrm{g} \mathrm{kg}^{-1}$, em plantas com oito meses.

Os teores de $\mathrm{Mg}$ variaram de 2,8 a 5,8 $\mathrm{g}$ $\mathrm{kg}^{-1}$ nas procedências de Barão de Cotegipe e Ivaí, respectivamente (Tabela 4). Para as progênies de Ivaí, obtiveram-se os teores mais elevados do nutriente, 
variando de 5,0 a $6,5 \mathrm{~g} \mathrm{~kg}^{-1}$ e para as de Barão de Cotegipe, teores de 2,1 a $4,2 \mathrm{~g} \mathrm{~kg}^{-1}$.

Estes resultados são comparáveis com os dados de Reissmann et al. (1983), que obtiveram níveis foliares de 2,7 a 5,0 $\mathrm{g} \mathrm{kg}^{-1}$; Sosa (1994), que obteve teor médio de $5,3 \mathrm{~g} \mathrm{~kg}^{-1} \mathrm{e}$ Rachwal et al. (2000) que, em povoamentos de erva-mate cultivada em Latossolo aos cinco anos de idade, determinaram teores que variaram de 3,8 a $5,6 \mathrm{~g}$ $\mathrm{kg}^{-1}$. No entanto, os resultados são inferiores aos encontrados por Fossati e Reissmann (1997) em ervais com experimento de calagem (CARNEIRO et al., 2006), onde encontraram níveis médios de $8,8 \mathrm{~g} \mathrm{~kg}^{-1}$. Independentemente destas considerações em relação a outras pesquisas que tratam da composição química das folhas, os resultados de $\mathrm{Ca}$ e $\mathrm{Mg}$ são bastante expressivos considerando que o solo apresenta, segundo a classificação dos níveis de fertilidade, níveis baixíssimos (COMISSÃO DE FERTILIDADE DO SOLO RS/SC, 2004).

Os teores de $\mathrm{Zn}$ obtidos nas procedências analisadas não apresentaram variação significativa, média 15,9 mg kg-1. Porém, quando analisadas separadamente, as progênies de Ivaí e Barão de Cotegipe, estas apresentaram diferenças significativas (Tabela 5). Deve-se destacar que, quando comparado com outras pesquisas, os resultados obtidos são muito baixos (PANDOLFO et al., 2003; REISSMANN e CARNEIRO, 2004). A concentração crítica de Zn em folhas de essências florestais varia de 15 a $30 \mathrm{mg}$ $\mathrm{kg}^{-1}$ (ABREU et al., 2001) logo, esses valores podem ser alterados com a idade da planta, concentração de outros nutrientes, principalmente com o fósforo. Teores abaixo de $20 \mathrm{mg} \mathrm{kg}^{-1}$ de $\mathrm{Zn}$ são indicativos de deficiência do nutriente na planta (DECHEN et al., 1991;ALLOWAY, 2004). A princípio, sem considerar a idade da planta, os teores obtidos encontram-se na concentração crítica. Provavelmente, esses baixos teores, na faixa de deficiência, sejam decorrentes de algum antagonismo iônico, ou efeitos de diluição, ou ainda, podem estar relacionados com a classe textural do solo (Tabela 5). Uma vez que o solo é muito argiloso e as argilas podem adsorver fortemente o $\mathrm{Zn}$, indisponibilizando-o para planta (GUPTA, 2001) ou podendo também ser fixado (DECHEN e NACHTIGAL, 2006). No entanto, de acordo com os teores mostrados na Tabela 5 e, relacionando os valores de referência da Comissão de Fertilidade do Solo RS/SC (2004), os teores no solo, são considerados altos para ambos os processos de extração e em especial para a extração com $\mathrm{HCl}$ $0,1 \mathrm{M}$.
Com relação ao $\mathrm{Fe}$, o teor mais elevado foi determinado para a procedência de Ivaí com média de $98,3 \mathrm{mg} \mathrm{kg}^{-1}$; e para a procedência de Barão de Cotegipe, de $85,7 \mathrm{mg} \mathrm{kg}^{-1}$. Relatos de estimativas de Fe têm sido variáveis. Os dados desse estudo, quando comparados com Reissmann et al. (1987), são satisfatórios. No entanto, são inferiores aos teores do nutriente em folhas maduras do morfotipo amarelinha de acordo com Robassa (2003) e elevados quando comparados com Pandolfo et al. (2003).

Os teores médios de $\mathrm{Cu}$ entre as procedências variaram de 7,7 e 11,8 $\mathrm{mg} \mathrm{kg}^{-1}$. Os teores do nutriente, quando comparados com os obtidos por Pandolfo et al. (2003) e Reissmann e Carneiro (2004), são satisfatórios. Comparados aos de Reissmann et al. (1983) e de Reissmann et al. (1987) os resultados são considerados inferiores, uma vez que os autores encontraram teores de 19 a $29 \mathrm{mg} \mathrm{kg}^{-1}$ e teor médio de $20 \mathrm{mg} \mathrm{kg}^{-1}$, respectivamente. No solo, os teores são considerados adequados (COMISSÃO DE FERTILIDADE DO SOLO RS/SC, 2004).

Os teores médios de Mn não foram diferentes entre as procedências. Dentro das progênies só foram constatadas diferenças entre as progênies de Barão de Cotegipe (Tabela 5). De modo geral, os teores de Mn variam bastante em erva-mate (REISSMANN et al., 1983; PANDOLFO et al., 2003, BORSOI e COSTA, 2001), uma vez que a espécie é tolerante a altíssimos níveis do nutriente (REISSMANN et al., 1987). O Mn é o micronutriente quantitativamente mais concentrado e exportado pela erva-mate (REISSMANN et al., 2003) sendo encontrados na espécie, teores de $3000 \mathrm{mg} \mathrm{kg}^{-1}$ (REISSMANN et al., 1999). Os teores altíssimos de Mn obtidos nas procedências de Barão de Cotegipe e Ivaí são coerentes com o levantado para a espécie, sendo que, Haridasan e Araújo (2005) consideraram, em suas pesquisas, plantas acumuladoras de $\mathrm{Mn}$ as espécies que apresentaram teores acima do limite de $300 \mathrm{mg} \mathrm{kg}^{-1}$. Assim, confirmando que a espécie em estudo pode ser considerada acumuladora do nutriente, bem como, as progênies de Ivaí e Barão de Cotegipe se enquadrariam como acumuladoras de Mn, uma vez que os teores encontrados nas progênies foram superiores ao limite encontrado pelos autores acima. Além disso, este aspecto do Mn é coerente com a análise de solo, tendo em vista que, já acima de $5 \mathrm{mg} \mathrm{kg}^{-1}$ solo, os teores de Mn são considerados altos. Nota-se que o solo do estudo apresenta um teor de até seis vezes mais. No caso do $\mathrm{Fe}$, discutido acima, nota-se o oposto. Os teores do 
solo em questão superam em até 60 vezes o valor mais alto da tabela de referência (COMISSÃO DE FERTILIDADE DO SOLO RS/SC, 2004), sendo que na planta são aproximadamente 20 vezes inferiores aos teores do $\mathrm{Mn}$.

Os teores de $\mathrm{B}$ entre as procedências variaram de 85 a $170 \mathrm{mg} \mathrm{kg}$. No entanto, entre as progênies não houve variação (Tabela 5). Ao se considerarem os altos teores de $\mathrm{B}$ encontrados, isto pode significar uma importante contribuição para a nutrição humana em termos de qualidade mineral da erva-mate, tendo em vista pesquisas na última década, demonstrando o importante papel do B no sistema cognitivo e psicomotor (PENLAND, 1994). De acordo com Amberger (1988), os teores de B podem apresentar ampla variação entre as espécies em geral. Este fato é apoiado por Jones Jr. (1998), onde o mesmo subdivide as plantas em três categorias que apresentariam limites de suficiência entre 6 a $100 \mathrm{mg} \mathrm{kg}^{-1}$, de acordo com a espécie. No caso da erva-mate não existe registro na literatura de níveis tão elevados (SOSA, 1994; REISSMANN et al., 1999; FOSSATI, 1997). Pesquisa realizada por Reissmann et al. (1999) determinou teores que variaram de 7 a $88 \mathrm{mg} \mathrm{kg}^{-1}$ e Pandolfo et al. (2003) teores médios de $60 \mathrm{mg} \mathrm{kg}^{-1}$. No entanto, por outro lado, nas análises registradas na literatura não consta discriminação por procedências ou progênies como foi feito no presente caso, o que pode explicar o atual nível encontrado.

No presente trabalho, os teores de B encontrados são elevados, quando comparados com outros autores que pesquisaram o nutriente na ervamate (PANDOLFO et al., 2003; REISSMANN et al., 1987; FOSSATI, 1997). Diante disso, Epstein e Blomm (2006) também enfatizam, como acima já citado por outros autores, que os teores de B nos tecidos foliares variam bastante, com teores de 5 a $300 \mathrm{mg} \mathrm{kg}^{-1}$ na matéria seca, o que tem respaldo em Amberger (1988) considerando diferentes espécies, porém, cujos limites se situam entre 2,3 a $95,0 \mathrm{mg} \mathrm{kg}^{-1}$.

Os teores médios de 695 a $726 \mathrm{mg} \mathrm{kg}^{-1}$ de $\mathrm{Al}$ não diferem estatisticamente entre as procedências analisadas (Tabela 5). No entanto, para as progênies de ambas as procedências, os teores obtidos apresentaram diferenças significativas. Os teores mais elevados de $\mathrm{Al}$ foram encontrados nas progênies 10 de Ivaí e 69 de Barão de Cotegipe. Os teores de Al nas progênies de Ivaí variaram de 562 a $832 \mathrm{mg} \mathrm{kg}^{-1}$, enquanto nas de Barão de Cotegipe, oscilaram entre 550 e $805 \mathrm{mg} \mathrm{kg}^{-1}$. A concentração de Al na erva-mate é bastante variada, uma vez que a planta pode ser considerada acumuladora de $\mathrm{Al}$ baseada nas pesquisas (CHENERY e SPORNE, 1976; HARIDASAN, 1982; HARIDASAN e

TABELA 5: Teores médios de micronutrientes, $\mathrm{Na}$ e $\mathrm{Al}\left(\mathrm{mg} \mathrm{kg}^{-1}\right)$ de progênies de erva-mate da procedência de Ivaí - PR e Barão de Cotegipe - RS.

TABLE 5: Average levels of micronutrients, $\mathrm{Na}$ and $\mathrm{Al}\left(\mathrm{mg} \mathrm{kg}^{-1}\right)$ of mate of the provenances of Ivaí, PR state e and Barão de Cotegipe, RS state.

\begin{tabular}{|c|c|c|c|c|c|c|c|}
\hline PROGÊNIE & $\mathrm{Zn}$ & $\mathrm{Fe}$ & $\mathrm{Cu}$ & $\mathrm{Mn}$ & B & $\mathrm{Al}$ & $\mathrm{Na}$ \\
\hline $04 \mathrm{IV}$ & $11,6 \mathrm{~b}$ & $106,9 \mathrm{ab}$ & $14,6 \mathrm{a}$ & $2038 \mathrm{a}$ & $166 \mathrm{a}$ & $632 \mathrm{~b}$ & $240 \mathrm{a}$ \\
\hline $08 \mathrm{IV}$ & $15,5 \mathrm{ab}$ & $118,8 \mathrm{a}$ & $13,1 \mathrm{ab}$ & $2201 \mathrm{a}$ & $169 \mathrm{a}$ & 828 a & $270 \mathrm{a}$ \\
\hline $10 \mathrm{IV}$ & $14,3 \mathrm{ab}$ & $104,3 \mathrm{~b}$ & $10,1 \mathrm{c}$ & $1800 \mathrm{a}$ & $184 \mathrm{a}$ & 832 a & $230 \mathrm{a}$ \\
\hline $11 \mathrm{IV}$ & $18,6 \mathrm{a}$ & $81,3 \mathrm{c}$ & $9,6 \mathrm{c}$ & $2164 \mathrm{a}$ & $184 \mathrm{a}$ & $562 \mathrm{~b}$ & $150 \mathrm{~b}$ \\
\hline $25 \mathrm{IV}$ & $16,6 \mathrm{ab}$ & $80,1 \mathrm{c}$ & $11,6 \mathrm{bc}$ & $2169 \mathrm{a}$ & $150 \mathrm{a}$ & 773 a & $160 \mathrm{~b}$ \\
\hline $53 \mathrm{BC}$ & $15,2 \mathrm{~b}$ & $90,5 \mathrm{ab}$ & $6,7 \mathrm{bc}$ & $1866 \mathrm{~b}$ & $87 \mathrm{a}$ & $550 \mathrm{~d}$ & $220 \mathrm{a}$ \\
\hline $59 \mathrm{BC}$ & $11,6 \mathrm{~b}$ & $97,3 \mathrm{a}$ & $10,8 \mathrm{a}$ & $1669 \mathrm{~b}$ & $81 \mathrm{a}$ & $656 \mathrm{~cd}$ & $270 \mathrm{a}$ \\
\hline $61 \mathrm{BC}$ & $16,8 \mathrm{ab}$ & $89,6 \mathrm{ab}$ & $8,3 \mathrm{~b}$ & $1809 \mathrm{~b}$ & $71 \mathrm{a}$ & $683 \mathrm{bc}$ & $170 \mathrm{~b}$ \\
\hline $65 \mathrm{BC}$ & $16,6 \mathrm{ab}$ & $80,1 \mathrm{bc}$ & $5,4 \mathrm{c}$ & $2203 \mathrm{ab}$ & $101 \mathrm{a}$ & $782 \mathrm{ab}$ & $220 \mathrm{a}$ \\
\hline $69 \mathrm{BC}$ & $22,3 \mathrm{a}$ & $70,9 \mathrm{c}$ & $7,4 \mathrm{bc}$ & $2616 \mathrm{a}$ & $85 \mathrm{a}$ & $805 \mathrm{a}$ & $230 \mathrm{a}$ \\
\hline Teor Médio -IV & $15,3 \mathrm{~A}$ & $98,3 \mathrm{~A}$ & $11,8 \mathrm{~A}$ & $2074 \mathrm{~A}$ & $170 \mathrm{~A}$ & $726 \mathrm{~A}$ & $210 \mathrm{~A}$ \\
\hline Teor Médio - BC & $16,5 \mathrm{~A}$ & $85,7 \mathrm{~B}$ & $7,7 \mathrm{~B}$ & $2033 \mathrm{~A}$ & $85 \mathrm{~B}$ & $695 \mathrm{~A}$ & $220 \mathrm{~A}$ \\
\hline
\end{tabular}

Em que: Para cada procedência, médias com as mesmas letras minúsculas, na vertical, não diferem estatisticamente ao nível de 5\% pelo teste de Duncan, no âmbito das progênies dentro de cada uma das procedências. Médias com as mesmas letras maiúsculas, na vertical, não diferem estatisticamente ao nível de $1 \%$ pelo teste de Duncan, no âmbito das procedências. IV = Ivaí, $\mathrm{BC}=$ Barão de Cotegipe. 
ARAÚJO, 2005) cuja classificação enquadra plantas acumuladoras de $\mathrm{Al}$ a partir de $1000 \mathrm{mg} \mathrm{kg}^{-1}$, sendo que este limite já foi superado (REISSMANN et al., 1987). Os resultados obtidos no presente estudo são elevados, quando comparados com Carneiro et al. (2006) e inferiores em relação aos de Reissmann et al. (1994). O mecanismo de tolerância ao Al ainda é desconhecido na erva-mate. Possivelmente esteja ligado a mecanismos que envolvem a ação de ácidos orgânicos, sabidamente envolvidos no processo de tolerância (MA et al., 2001). No entanto, os teores de Al obtidos nas progênies de erva-mate, nessa pesquisa, não a enquadrariam como acumuladora de Al (Tabela 5), devido ao fato das progênies apresentaram teores abaixo de $1000 \mathrm{mg} \mathrm{kg}^{-1}$.

Com relação ao Na não se obteve diferença significativa para as procedências analisadas. Foram obtidos teores médios de 210 e $220 \mathrm{mg} \mathrm{kg}$ 1, respectivamente, para a procedência de Ivaí e Barão de Cotegipe. Porém, constatou-se diferença significativa para as progênies de ambas as procedências (Tabela 5). Teores de 150 a $270 \mathrm{mg}$ $\mathrm{kg}^{-1}$ foram determinados para as progênies de Ivaí e teores de 170 a $270 \mathrm{mg} \mathrm{kg}^{-1}$ para as progênies de Barão de Cotegipe. Os teores de $\mathrm{Na}$ obtidos no presente estudo são altos quando comparados com Santin (2008) que encontrou teor médio de $138,0 \mathrm{mg}$ $\mathrm{kg}^{-1} \mathrm{em}$ erva-mate adensada submetida a diferentes doses de NPK no município de São Mateus do Sul -PR. Ducat e Quinália (2004) obtiveram teores variando de 36,91 a $54,17 \mathrm{mg} \mathrm{kg}^{-1} \mathrm{em}$ erval nativo e cultivado, respectivamente, na região CentroOeste do Estado do Paraná. Entretanto, Kaseker et al. (2010), na mesma área amostral deste estudo, obtiveram teores de $163,23 \mathrm{mg} \mathrm{kg}^{-1}$ para o morfotipo amarelinha da procedência Ivaí e $104,37 \mathrm{mg} \mathrm{kg}^{-1}$ para o morfotipo sassafrás da procedência Barão de Cotegipe.

\section{CONCLUSÕES}

Os teores de macronutrientes $\mathrm{N}, \mathrm{P}, \mathrm{K}, \mathrm{Ca}$ e $\mathrm{Mg}$ foram considerados satisfatórios tanto para procedência de Ivaí, quanto para Barão de Cotegipe. Porém, os teores de $\mathrm{N}, \mathrm{P}, \mathrm{Ca}$ e $\mathrm{Mg}$ apresentaram diferença significativa entre as procedências analisadas.

Os teores foliares de $\mathrm{Fe}, \mathrm{Cu}$ e $\mathrm{Mn}$ foram considerados satisfatórios para ambas as procedências, no entanto, foi obtida baixa concentração de $\mathrm{Zn}$, elevada de $\mathrm{B}$ e $\mathrm{Na}$ e teores normais de $\mathrm{Al}$ para a espécie. Os teores de $\mathrm{Fe}, \mathrm{Cu}$ e
B diferiram estatisticamente entre as procedências.

A procedência de Ivaí apresentou teores mais elevados tanto de macro como de micronutrientes, comparativamente à procedência de Barão de Cotegipe, indicando que um programa de melhoramento genético poderá refletir significativamente na melhoria da qualidade da erva-mate.

Ao se compararem as médias da massa fresca das procedências, há ganho significativo da copa da procedência de Barão de Cotegipe, o que não é acompanhado pelo peso da massa seca de 100 folhas.

\section{AGRADECIMENTOS}

A ervateira Bitumirim, UFPR e a Embrapa Florestas-CNPF.

\section{REFERÊNCIAS BIBLIOGRÁFICAS}

ABREU, C. A.; FERREIRA, M. E; BORKERT, C. M. Disponibilidade e avaliação de elementos catiônicos: zinco e cobre. In: FERREIRA, M.E; CRUZ, M.C. P. da; RAIJ, B. van.; ABREU, C. A. Micronutrientes e elementos tóxicos na agricultura. Jaboticabal: $\mathrm{CNPq} / \mathrm{FAPESP} /$ POTAFOS, 2001. p. 125 - 150.

ALLOWAY, B. J. Zinc in soils and crop nutrition. 2004. 116 p. Disponível em: < (http://www.zinccrops.org/Crops/Alloway-all.php) > . Acesso em: 20 de Junho de 2007.

AMBERGER, A. Pflanzenernährung. Stuttgart: Verlag Eugen Ulmer. 1988. 264 p.

BORILLE, A. M.; REISSMANN, C. B.; FREITAS, R. J. S. Relação entre compostos fotoquímicos e o $\mathrm{N}$ em morfotipos de erva-mate (Ilex paraguariensis St. Hil). B. CEPPA, Curitiba, v. 23, n. 1. p. 183-198, jan./jun. 2005.

BRONDANI, G.E. et al. Distribuição de N P K em um povoamento de Ilex paraguariensis A. St. Hil. Floresta, Curitiba, v. 38, n. 2, p. 267-275, abr./jun. 2008.

BORSOI, G. A., COSTA, E. C. Avaliação nutricional de plantas de erva-mate atacadas e não atacadas pelo Hedypathes betulinus (Klug, 1825). Ciência Florestal, Santa Maria, v. 11, n. 2, p. 131-142, 2001. CALDEIRA, M. V. W. et al. Quantificação da biomassa acima do solo de Acacia mearnsii de Wild., procedência Batemans bay - Austrália. Ciência Florestal, Santa Maria, v. 11, n. 2, p. 79-91, 2001. 
CARNEIRO, C; REISSMANN, C. B.; MARQUES, R. Comparação de Métodos de Análise Química de $\mathrm{K}, \mathrm{Ca}, \mathrm{Mg}$ e $\mathrm{Al}$, em folhas de erva-mate (Ilex paraguariensis St. Hil.) Revista Cerne, Lavras, v. 12, n. 2, p. $113-122$, abr./jun. 2006.

CHENERY, E. M.; SPORNE, K. R. A note on the evolutionary status of aluminium-accumulators among dycotiledons. New Phytologist, EUA, v. 76, n.3, p.551-554, Jan./Mar. 1976.

COELHO, G. C. et al. Efeito do sombreamento sobre a sobrevivência, morfologia e química da erva-mate. In: CONGRESSO SUL-AMERICANO DE ERVA-MATE, 2; REUNIÃO TÉCNICA DA ERVA-MATE, 3., 2000. Anais... Porto Alegre, Ed. Dos Organizadores, 2000. p. 396-399.

SOCIEDADE BRASILEIRA DE CIÊNCIA DO SOLO. COMISSÃO DE QUÍMICA E FERTILIDADE DO SOLO - RS/SC. Manual de adubação e calagem para os Estados do Rio Grande do Sul e de Santa Catarina. 10. ed., Porto Alegre: SBCS, Comissão de Química e Fertilidade do Solo, 2004. 394 p.

COSTA, R. B. da. et. al. Avaliação genética de indivíduos de erva-mate (Ilex paraguariensis $\mathrm{St}$. Hil.) na região de Caarapó, MS, pelo procedimento REML/BLU. Ciência Florestal, Santa Maria, v. 15, n. 4, p. 371-376, Nov. 2005.

DECHEN, A. R.; HAAG, H. P.; CARMELLO, Q. A. C. Avaliação do estado nutricional da planta e disponibilidade no solo. In: FERREIRA, M.E.; CRUZ, M.C.P (Ed.). Micronutrientes na agricultura. Piracicaba: POTAFOS/CNPq, 1991. p. 65-78.

DECHEN, A. R.; NACHTIGAL, G. R. Micronutrienes. In: FERNANDES, M. S. (Ed.), Nutrição Mineral de Plantas. Viçosa: SBCS, 2006. p.327-354.

DUCAT, G.; QUINÁLIA, S. P. Avaliação do teor de minerais da Ilex paraguariensis da região CentroOeste do Estado do Paraná. Revista Ciências Exatas e Naturais, Unicentro, v. 6, n. 1, 31-42 p, jan/jun 2004.

EMBRAPA Serviço nacional de levantamento e conservação do solo: Manual de métodos e análise de solos. Rio de Janeiro, 1979. 650 p.

EPSTEIN, E.; BLOOM, A. J. Nutrição Mineral de Plantas: princípios e perspectivas. Londrina: Planta, 2006. $403 \mathrm{p}$.

FIEDLER,H. J.; NEBE, W.; HOFFMANN, F. Forstliche Pfanzenernährung and Düngung. Stuttgart: Gustav Fischer Verlag, 1973, 481 p.

FLOSS, P. A. Programa de melhoramento genético da erva-mate na EPAGRI. In: CONGRESSO SULAMERICANO DA ERVA-MATE, 1. REUNIÃO TÉCNICA DO CONE SUL SOBRE A CULTURA DAERVA-MATE, 2. Anais...Colombo:EMBRAPACNPF, 1997. p. 279.

FOSSATI, L.C.; REISSMANN, C.B. Avaliação do estado nutricional e da produtividade de Ilex paraguariensis St. Hil. (erva-mate), em função do sitio. In: CONGRESSO SUL-AMERICANO DA ERVA-MATE, 1.; REUNIÃO TÉCNICA DO CONE SUL SOBRE A CULTURA DA ERVA-MATE, 1., 1997, Colombo. Anais... Colombo:Embrapa-CNPF, 1997.

FOSSATI, L. C. Avaliação do estado nutricional e da produtividade da erva-mate (Ilex paraguariensis St. Hil.) em função do sítio e da dioicia. 1997. 113 f. Dissertação (Mestrado em Engenharia Florestal) - Universidade Federal do Paraná, Curitiba, 1997.

GREGIANINI, T. S.; WINGE, H. Variabilidade de proteínas de reserva em populações naturais de erva-mate (Ilex paraguariensis A. St. Hil., Aquifoliaceae). In: CONGRESSO SULAMERICANO, 2.; REUNIÃO TÉCNICA DA ERVA-MATE, 3., 2000, Encantado. Anais... Porto Alegre: Edição dos organizadores, 2000. p. $373-380$.

GREIZERSTEIN, E. J. et al. Espécies de Ilex Del Cono Sur: Estúdios Citogenéticos y de Electroforesis de Proteínas. In: CONGRESSO SULAMERICANO DA ERVA-MATE, 2.; REUNIÃO TÉCNICA DA ERVA-MATE, 3. 2000, Encantado. Anais... Porto Alegre: Edição dos Organizadores, 2000. p. 116-120.

GUPTA, U. C. Micronutrientes e elementos tóxicos em plantas e animais. In: FERREIRA, M. E.; CRUZ, M. C. P.; RAIJ, B. VAN; ABREU, C. A. Micronutrientes e elementos tóxicos na agricultura. Jaboticabal: $\mathrm{CNPq} / \mathrm{FAPESP} /$ POTAFOS, 2001. p. 13-42.

HARIDASAN, M. Nutrição mineral de plantas nativas do Cerrado. Revista Brasileira de Fisiologia Vegetal. São Paulo. v. 12, n. 1, p. 54 -64, Nov. 2000. HARIDASAN, M.ARAÚJO, G.M. Perfil nutricional de espécies de duas florestas semidecíduais em Uberlândia, MG. Revista Brasileira de Botânica. São Paulo. v. 28. n. 2, p. 295 - 303, abr./jun. 2005. HARIDASAN, M. Aluminium accumaliton by some cerrado native species of central Brazil. Plant and Soil. London, v. 65. n. 2, p. $265-273,1982$. IAPAR. Cartas climáticas básicas do Estado do Paraná. Londrina: Fundação Instituto Agronômico 
do Paraná, 1994. 49 p. (Documentos; 18). IBGE, Produção da extração vegetal e silvicultura, v. 24, 2009. 42 p. Disponível em < (http://www. ibge.gov.br/home/estatistica/economia/pevs/2009/ pevs2009.pdf) > Acesso em: 02 de outubro de 2011. JONES JR, J. B.; CASE, V. W. Sampling, hadling and analyzing plant tissue samples. In: WESTERMANN et al. Soil testing and plant analysis. 3rd Ed. (EDS). SSSA, Book Series. 1990, 389-420 p.

JONES JUNIOR, J. B. Plant Nutrion Manual. Boca Raton: CRC, 1998, 149 p.

JONES JUNIOR, J. B.; CASE, V. W. Sampling handling, and analyzing plant tissue samples. In: WESTERMAN et al (eds) Soil testing and plant analysis. Madison: SSSA Book Series, 1990. 427 p. KASEKER, J. F. et al. Análise química foliar compartimentada em folhas e talos de morfotipos e procedências de erva-mate. In: REUNIÃO BRASILEIRA DE FERTILIDADE DO SOLO E NUTRIÇÃO DE PLANTAS, 29.; REUNIÃO BRASILEIRA SOBRE MICORRIZAS, 13.; SIMPÓSIO BRASILEIRO DE MICROBIOLOGIA DO SOLO, 11.; VIII REUNIÃO BRASILEIRA DE BIOLOGIA DO SOLO, 8., 2010, Guarapari - ES. Anais... 2010. CD ROM.

MA, J. F.; RYAN, P. R.; DELHAIZE, A. Aluminium tolerance in plants and the complexing role of organic acids. Trends Plant Science, London, v. 6, n. 6, p. 273-278, jun. 2001.

MACCARRI JUNIOR, A; MAZUCHOWSKI, J. Z. Produtos alternativos e desenvolvimento da tecnologia industrial na cadeia produtiva da ervamate. Câmara setorial da cadeia produtiva da ervamate /MCT /CNPQ /Projeto PADCT - Erva-mate. Curitiba - Paraná, 160 p. 2000.

MALAVOLTA, E. Elementos de nutrição mineral de plantas. São Paulo:Agronômica Ceres, 1980. $251 \mathrm{p}$.

MALAVOLTA, E.; VITTI, G. C.; OLIVEIRA, S.A. Avaliação do estado nutricional das plantas: princípios e aplicações. Piracicaba: Ed. Associação Brasileira para Pesquisa da Potassa e do Fosfato, 1997. 319 p.

MARTINS, A. P. L; REISSMANN, C. P. Material Vegetal e Rotinas Laboratoriais nos procedimentos químicos-analíticos. Scientia Agrária, Curitiba, v. 8, n. 1, p. 1-17, 2007.

OLIVEIRA, Y. M. M. de; ROTTA, E. Área de distribuição natural de erva-mate (Ilex paraguariensis St. Hil). In: SEMINÁRIO SOBRE ATUALIDADES E PERSPECTIVAS
FLORESTAIS - SILVICULTURA DA ERVAMATE 10., 1985, Curitiba. Anais. Curitiba, EMBRAPA/CNPF, 1985. p. 17 - 35.

PANDOLFO, C. M.; FLOSS, P. A.; CROCE, D. M. da; MITTRICH, R. C. Resposta da erva-mate (Ilex paraguariensis St. Hil.) à adubação mineral e orgânica em um latossolo vermelho aluminoférrico. Ciência Florestal, Santa Maria, v. 13, n. 2, p. 3745, nov. 2003.

PENLAND, G. Dictory Boron, Brain Function and Cognitive Performance. Enviromental Health Perspectivas, North Dakota, v.102, n. 7, Nov. 1994. PERKIN-ELMER. Analytical methods of atomic absorption spectrophotometry: analytical methods agriculture: section AYII:analysis of feedsnorwalk. Perkin: Elmer Corporation, 1976.476 p.

PEREIRA, J. C. et al. Estimativa do conteúdo de nutrientes em um povoamento de Acácia mearnsii De Wild. no Rio Grande do Sul - Brasil. Revista Árvore, Viçosa, v. 24, n. 2, p. 193-199, jan./fev. 2000.

RACHWAL, M. F. et. al. Influência da luminosidade sobre os teores de macronutrientes e taninos em folha de erva-mate. In: CONGRESSO SULAMERICANO DE ERVA-MATE, 2; REUNIÃO TÉCNICA DA ERVA-MATE, 3, 2000, Porto Alegre. Anais... Porto Alegre: Ed. Dos Organizadores, 2000. p.417- 420

RADOMSKI, M. I.; SUGAMOSTO, N. F. B.; CAMPIOLO, S. Avaliação dos teores de macro e micronutrientes em folhas jovens e velhas de erva-mate nativa. Revista do Instituto Florestal, São Paulo, v. 4, p. 453-456, mar. 1992.

REISMANN, C. B; RADOMSKI, M. I e QUADROS, R. M. B. Relação entre os teores totais e hidrossolúveis dos elementos $\mathrm{K}, \mathrm{Ca}, \mathrm{Mg}$, $\mathrm{Fe}, \mathrm{Mn}, \mathrm{Cu}, \mathrm{Zn}$ e $\mathrm{Al}$ em folhas de erva-mate (Ilex paraguariensis St. Hil). Arquivos de Biologia de Tecnologia, Curitiba, v. 37, n. 4. p. 959-971, 1994.

REISSMANN, C. B. et al. Níveis foliares e exportação de micronutrientes pela exploração da erva-mate. Revista do Setor de Ciências Agrárias, Curitiba, v. 9, p. 103-106, 1987.

REISSMANN, C. B.; ROCHA, H. O. DA ; KOEHLER, C. W. Bioelementos em folhas e hastes de erva-mate (Ilex paraguariensis St. Hil.) sobre cambissolo na região de Mandirituba - PR. Curitiba. Floresta, Curitiba, v. 14, n. 2. p. 49-54, 1983.

REISSMANN, C. B. et al. Production and foliar $\mathrm{N}, \mathrm{P}, \mathrm{K}, \mathrm{Ca}$ and $\mathrm{Mg}$ levels in erva-mate (Ilex paraguariensis St. Hil.) related to increasing base 
saturation levels. Arq. Biol. Tecnol, Curitiba, v. 40, n. 1, p. 241-249, 1997.

REISSMANN, C. B.; RADOMSKI, M. I.; QUADROS, R. M. B de. Chemical composition of Ilex paraguariensis St. Hil. under different management conditions in seven localites of Paraná State. Brazilian Archives of Biology and Technology, v. 42, n. 2, p.187-194, 1999.

REISSMANN, C. B; CARNEIRO, C. Crescimento e Composição química de erva-mate (Ilex paraguariensis St. Hil.), transcorridos oito anos de calagem. Floresta, Curitiba, v. 34. n. 3, p. 381-386, set./dez. 2004.

REISSMANN, C. B. et al. Calibração preliminar de $\mathrm{Fe}$ e $\mathrm{Mn}$ em erva-mate utilizando a análise foliar e extração do solo com ácido cítrico $1 \%$ e ácido clorídrico $1 \mathrm{~mol} \mathrm{~L}^{-1}$. In: CONGRESSO SUL AMERICANO DE ERVA-MATE, 3.; FEIRA DO AGRONEGÓCIO DA ERVA-MATE, 1., 2003, Chapecó. Anais... Ed. News Print, 2003. 1 CD ROM.

REISSMANN, C.B. et al. Bio-elementos em folhas e hastes de erva-mate (Ilex paraguariensis St. Hil) sobre cambissolos na região de Mandirituba-PR. Floresta, Curitiba, v. 16, n. 2, p. 49-54, 1983.

REISSMANN, C. B.; ZÖTTL, H. W. Problemas nutricionais em povoamentos de Pinus taeda em áreas de arenito da formação Rio Bonito - Grupo Guatá. Revista do Setor de Ciências Agrárias, Curitiba, v.9, p. 75-80, 1987.

RESENDE,M.D.V. etal.Programa demelhoramento da erva-mate coordenado pela Embrapa: resultados da avaliação genética de populações, progênies, indivíduos e clones. Circular Técnica, Colombo, n. 43, 2000.

RESENDE, M. D. V.; STURION, J. A, MENDES, S. Genética e melhoramento da erva-mate (Ilex paraguariensis St. Hil). Colombo: EMBRAPACNPF, 1995. $33 \mathrm{p}$.

RIBEIRO, M. M.; REISSMANN, C.B.; CORRÊA, D.R. Nutrição da erva-mate com Sulfato de Amônio. Cerne, Lavras, v. 14, n. 3, p. 204 - 211, 2008.

ROBASSA, J. C.; REISSMANN, C. B.; MACCARI JUNIOR, A. Teores de Fe, $\mathrm{Mn}, \mathrm{Cu}$ e $\mathrm{Zn}$ em três morfotipos de erva-mate (Ilex paraguariensis St. Hil.). In: CONGRESSO SUL-AMERICANO DA ERVA-MATE, 3.; FEIRA DO AGRONEGÓCIO DA ERVA-MATE, 1., 2003,Chapecó. Anais... 2003. CD ROM.

RODIGHERI, H. R.; DOSSA, D.; VIELCAHUAMAN, L. J. M. Cultivo da ErvaMate: Importância Socioeconômica e Ambiental.
Embrapa/Florestas. 2005. Disponível em < (http://sistemasdeproducao.cnptia.embrapa.br/ FontesHTML/Erva-mate/CultivodaErvaMate/01 importancia_socioec.htm) $>$ Acesso em: 03 de outubro de 2011.

SANTIN, D. Produtividade, teor de minerais, cafeína e teobromina em erva-mate adensada e adubada quimicamente. 2008. 114 f. Dissertação (Mestrado em Ciência do Solo) - Universidade Federal do Paraná, Curitiba, 2008.

SILVA, F. C. Manual de análises químicas de solos, plantas e fertilizantes. Brasília: Embrapa Solos, 1999. $370 \mathrm{p}$.

SOSA, A. D. Evaluación de la production de yerba mate em relacion al estado nutricional suelo/ planta. In: CURSO DE CAPACITACION EN LA PRODUCION DE YERBA MATE, 1., 1992, Cerro Azul. Anais... Cerro Azul: INTA, 1994. p. 61-64.

ULRICH, A.; HILLS, F. J. Plant analysis as na aid in sugarbeet. In: WESTERMANN et al. Soil Testing and Plant analysis. Madison: SSSA Book Series, 1990. $446 \mathrm{p}$.

VAN DER DRIESSCHE, R. Nutrient Storage, retranslocation and relation ship of stress to nutrition. In: NUTRITION OF PLANTATION FOREST, 1984, Londres. Anais... Bowen: Academic Press, 1984. p. 181-209.

VOGEL, H. L. M., SCHUMACHER, M. V., TRÜBY, P. Quantificação da biomassa em uma floresta estacional decidual em Itaara, RS, Brasil. Ciência Florestal, Santa Maria, v. 16, n. 4, p. 419-425, out./dez. 2006.

WINGE, H. Conservação genética da erva-mate no Brasil. In: CONGRESSO SUL-AMERICANO DA ERVA-MATE, 1.; REUNIÃO TÉCNICA DO CONE SUL SOBRE A CULTURA DA ERVA-MATE, 2 ., 1997, Curitiba. Anais... Curitiba: EMBRAPA, 1997. p $211-223$.

WISNIEWSKI, C. et al. Exportação de biomassa e macronutrientes com a primeira poda de formação da erva-mate na região de Pinhais - PR. Revista do Setor de Ciências Agrárias, Curitiba, v.15, p.179-186, 1996.

ZAMPIER, A. C. Avaliação dos níveis de nutrientes, cafeína e taninos após adubação mineral e orgânica e sua relação com a produtividade na erva-mate (Ilex paraguariensis St. Hil). In: CONGRESSO SUL-AMERICANO DA ERVA-MATE, 3.; FEIRA DO AGRONEGÓCIO DA ERVA-MATE, 1., 2003, Chapecó. Anais... 2003. CD-ROM.

ZONTA, E.P;MACHADO, A. A. Sistema de Análise 
Estatística (SANEST) para microcomputadores. ZÖTTL, H. M. Diagnosis of nutricional In: SIMPÓSIO DE ESTATÍSTICA APLICADA À disturbances in Forest stands. In: FAO/IUFRO. EXPERIMENTAÇÃO AGRONÔMICA, 1., 1985, INTERNATIONAL SYMPOSIUM ON FOREST Piracicaba. Anais. Campinas: Fundação Cargil. FERTILIZATION. 1973, Paris. Anais...Paris: 1985. p.91-99. Ministére de l'Agriculture, 1973. p. 75-95. 